\title{
Effectiveness of structured teaching programme regarding polycystic ovarian syndrome among adolescent girls
}

\author{
Soniya John* \\ KUHS, OBG Nursing, SSNMM College of Nursing, Trivandrum, Kerala, India
}

Received: 12 May 2021

Revised: 21 June 2021

Accepted: 22 June 2021

\section{*Correspondence:}

Mrs. Soniya John,

E-mail: soniajohn9@gmail.com

Copyright: $\odot$ the author(s), publisher and licensee Medip Academy. This is an open-access article distributed under the terms of the Creative Commons Attribution Non-Commercial License, which permits unrestricted non-commercial use, distribution, and reproduction in any medium, provided the original work is properly cited.

\begin{abstract}
Background: Polycystic ovary syndrome is an endocrine disorder that affects approximately $5 \%$ of all women. It occurs amongst all races and nationalities. It is the most common hormonal disorder among women of reproductive age and is a leading cause of infertility. As polycystic ovarian syndrome is an ovarian disorder marked by a lack of estrogen, hyperandrogenaemia, obesity, hyper insulinaemia and starts early in the adolescent period. So, we should teach them regarding the clinical features treatment and prevention.

Methods: A quasi experimental one group pre-test post design was adopted to assess the effectiveness of structured teaching programme on knowledge regarding polycystic ovarian syndrome among adolescent girls, Bangalore. A sample of 60 adolescent girls was selected from NRI higher secondary school, Bangalore by purposive sampling technique. Collected data was analysed by using descriptive and inferential statistics.

Results: More than half 54 (90.0\%) were having inadequate knowledge and $6(10 \%)$ were having moderate knowledge regarding PCOS before STP.

Conclusions: Structured teaching programme was significantly effective in increasing the knowledge of polycystic ovarian syndrome. The most important role of the nurse is to provide awareness on prevention and health promotion.
\end{abstract}

Keywords: Adolescent girls, Structured teaching programme, PCOS

\section{INTRODUCTION}

During adolescent period the individual becomes capable of reproduction. The adolescent is prone to suffer from medical and health problems peculiar to this age period. Polycystic ovary syndrome is an endocrine disorder that affects women of reproductive age and is a leading cause of infertility. ${ }^{1}$ The causes are unknown, insulin resistance, diabetes, and obesity are all strongly correlated with polycystic ovarian syndrome. ${ }^{2}$ Adolescent girls are often associated with oligomenorrhea, amenorrhea- irregular, few, or absent menstrual periods, Hirsutism- excessive and increased body hair, typically in a male pattern affecting face, chest and legs. Hair loss appearing as thinning hair on the top of the head acne, oily skin, seborrhea. Obesity or weight gain: one in two women with PCOS are obese, depression and deepening of voice. All these are due to immaturity of the hypothalamic pituitary ovarian axis during the first years following menarche. ${ }^{3}$ During adolescent period general interventions like weight reduction, regular exercise and maintaining a healthy weight can reduce hormonal imbalance, restore ovulation and fertility, and improve acne and hirsutism. ${ }^{4}$

Between 1 in 10 and 1 in 20 women of childbearing age has PCOS. As many as 5 million women in the United States may be affected. It can occur in girls as young as 11 years old. The cause of PCOS is unknown. Women with PCOS are more likely to have a mother or sister with PCOS. ${ }^{5}$ 
A main underlying problem with PCOS is a hormonal imbalance. Insulin is a hormone that controls the change of sugar, starches, and other food into energy for the body to use or store. Many women with PCOS have too much insulin in their bodies because they have problems using it. Excess insulin appears to increase production of androgen. ${ }^{6}$ A clinical prediction rule found that these four questions can diagnose PCOS with a sensitivity of $77.1 \%$ (95\% CI $62.7 \%-88.0 \%)$ and a specificity of $93.8 \%(95 \%$ CI $82.8 \%-98.7 \%){ }^{7}$

According to the Rotterdam criteria, 12 or more small follicles should be seen in an ovary on ultrasound examination. The follicles may be oriented in the periphery, giving the appearance of a 'string of pearls'. The numerous follicles contribute to the increased size of the ovaries, that is, 1.5 to 3 times larger than normal. ${ }^{8}$ Serum (blood) levels of androgens (male hormones), including androstenedione, testosterone and dehydroepiandrosterone sulfate may be elevated. The free testosterone level is thought to be the best measure with $\sim 60 \%$ of PCOS patients demonstrating supra-normal levels. ${ }^{9}$

The Free androgen index of the ratio of testosterone to sex hormone-binding globulin (SHBG) is high, is meant to be a predictor of free testosterone, but is a poor parameter for this and is no better than testosterone alone as a marker for PCOS, possibly because FAI is correlated with the degree of obesity. ${ }^{10}$ The ratio of LH (luteinizing hormone) to FSH (follicle stimulating hormone) is greater than 1:1, as tested on day 3 of the menstrual cycle. The pattern is not very specific and was present in less than $50 \%$ in one study. ${ }^{11}$ Insulin resistance can be observed in both normal weight and overweight patients. ${ }^{12}$ Reproductive disorders in children range from mild infections to serious anatomic malformations. All of these require prompt and careful treatment so that we have to make them aware of normal reproductive health and its abnormalities. Then only they can identify abnormalities and treat promptly. ${ }^{13}$ So we should teach them regarding the clinical features treatment and prevention. ${ }^{14}$

In another study it is reported that prevalence of polycystic ovarian disease may be as high as $11.2 \%$ in women of reproductive years of that age group adolescent girls make up $50 \%$ when dealing with teenagers $98 \%$ of cyst in younger are benign. ${ }^{15}$ More research is necessary in order to find answers to many clinical and theoretical aspects of the syndrome. ${ }^{16}$ Recent research has shown that the application of diabetes management techniques aimed at reducing insulin resistance and hyperinsulinaemia (such as weight reduction and the administration of oral hypoglycaemic agents) can not only reverse testosterone and $\mathrm{LH}$ abnormalities and infertility, but can also improve glucose, insulin and lipid profiles. ${ }^{17}$ With the discovery of the common association between insulin resistance and polycystic ovarian syndrome, however, able to utilize a new class of systemically targeted drugs that work on many of the symptoms found in these women. ${ }^{18}$ Women with PCOS, diagnosed and managed properly, can benefit from the reduction or even reversal of the reproductive and metabolic morbidities and from the reduction of the risk factors for cardiovascular disorders. ${ }^{19}$ All these data provoked the researcher to take this initiation of conducting the study.

\section{METHODS}

Current study was conducted among adolescent girls between 16-20 years in NRI higher secondary school, Bangalore in August 2010. Quasi experimental one group pre-test, post-test design and non-probability purposive sampling method was adopted. Plus, one and plus two classes taken for study who fulfil inclusion criteria (adolescent girls who are studying at the selected school aged between 16-20 years and who can speak and understand English and Kannada).

Exclusion criteria includes adolescent girls who are not willing to participate and who are not available during the study. The tool used in the study was a structured knowledge questionnaire which consists of 4 sections. Section A- demographic data consists of ten items seeking information on demographic data which includes age, age at menarche, menstrual pattern, pain present, dietary pattern, educational status, family income, religion, type of family, family history of PCOS and source of information. Section B- assessment of knowledge consists of 34 questions was under six headings. Knowledge regarding anatomy and physiology of the female reproductive system- 16 items, meaning of PCOS- 2 items, risk factors3 items, pathology and manifestation-5 items, detection and management-5 items, and general care of PCOS-3 items. Each correct answer was given a score one mark and incorrect answer was given a score zero mark. The maximum score was 34 and the minimum score was zero. To interpret level of knowledge the scores were distributed as inadequate knowledge: $<50 \%$, moderate knowledge: $50-75 \%$, adequate knowledge: $>75 \%$. Formal written permission was obtained from Principal of NRI higher secondary school, Bangalore. Prior to data collection the researcher introduced herself and explained the purpose of the study.

The informed consent was obtained from the samples; the samples were assured the anonymity and confidentiality of the information provided them. Data collection process done as- Phase I: pretest was conducted through structured knowledge questionnaire along with adequate explanation for about 20-30 minutes, Phase II: the researcher administered the structured teaching programme (STP) to each participant on the same day of data collection, and Phase III: After 7 days of administration of structured teaching programme, the posttest was conducted to the same subjects by using same structured knowledge questionnaire. The collected data was analyzed by using descriptive statistics: frequency and percentage distribution mean and standard deviation was used to assess demographic variables and level of 
knowledge regarding polycystic ovarian syndrome. Mean and standard deviation were used to analyze the level of knowledge regarding on polycystic ovarian syndrome among adolescents. Inferential statistics: Paired ' $t$ ' test were used to analyze the difference between mean pre-test and post-test knowledge regarding PCOS among adolescent girls. Chi-square tests were used to analyze the association between level of knowledge regarding PCOS among adolescent girls with their selected demographic variables. Independent variable in the present study is structured teaching programme and the dependent variable is knowledge of adolescent girls.

For the present study the investigator took into consideration the ethical issue. The study was approved by the research committee and formal permission was taken from Principal of Varalakshmi College of Nursing, Bangalore. Formal permission was obtained from the principal of NRI higher secondary school, Bangalore. Informed consent was obtained from the study sample (adolescent girls). The subjects were informed that their participation was purely on the voluntary basis and they can withdraw from the study at any time. No ethical issues arouse during the study.

\section{RESULTS}

Current study shows more than half 54 (90.0\%) were having inadequate knowledge and $6(10 \%)$ were having moderate knowledge regarding PCOS before STP. Table 1 describes distribution of adolescents to their sociodemographic variables. According to age there is an equal proportion of age group between 16-17 and 18-19 years. Regarding age of menarche majority attained in between 15-16 years. A majority of $68.3 \%$ is having regular menstrual pattern. According to pain condition $55 \%$ of them are having mild pain and $40 \%$ having moderate pain. Regarding diet pattern $71.7 \%$ belongs to non-vegetarian category.

According to educational level $63.3 \%$ were studying in plus two class. According to family income equal proportion $46.7 \%$ of with them in the category of $<$ Rs.5000 and Rs.5001-10000. Regarding religion majority of $75 \%$ were belongs to Hindu religion. Of them $66.7 \%$ belongs to nuclear family. Out of the subjects studied a majority $68.3 \%$ have no family history of PCOS and $31.7 \%$ having family history of PCOS. According to source of information more than half $53.3 \%$ is having information through health personnel.

Figure 3 shows a majority $90 \%$ had inadequate knowledge, $10 \%$ had moderate knowledge and none of them have adequate knowledge regarding PCOS before teaching programme. But a majority of $80 \%$ had adequate knowledge, $20 \%$ had moderate knowledge and none of them had inadequate knowledge after structured teaching programme.

Chi square analysis shows (Table 3 ) association between post-test knowledge regarding PCOS among adolescent girls and their selected sociodemographic variables which included age at menarche, pain present and family history of PCOS at $5 \%$ level.

Table-1: Distribution of adolescent girls according to demographic variables $(\mathrm{N}=60)$.

\begin{tabular}{|c|c|c|c|}
\hline \multirow{2}{*}{ Characteristics } & \multirow{2}{*}{ Category } & \multicolumn{2}{|c|}{ Respondents } \\
\hline & & Number & Percent (\%) \\
\hline \multirow{4}{*}{ Age (years) } & Below 16 & - & - \\
\hline & $16-17$ & 30 & 50.0 \\
\hline & $18-19$ & 30 & 50.0 \\
\hline & 20 and above & - & - \\
\hline \multirow{4}{*}{ Age at menarche (years) } & Below 12 & 5 & 8.3 \\
\hline & $13-14$ & 23 & 38.3 \\
\hline & $15-16$ & 32 & 53.3 \\
\hline & $>16$ & - & - \\
\hline \multirow{3}{*}{ Menstrual pattern } & Regular & 41 & 68.3 \\
\hline & Irregular & 19 & 31.7 \\
\hline & Anovulation & - & - \\
\hline \multirow{3}{*}{ Pain present } & Mild & 33 & 55.0 \\
\hline & Moderate & 24 & 40.0 \\
\hline & Severe & 3 & 5.0 \\
\hline \multirow{3}{*}{ Dietary pattern } & Vegetarian & 17 & 28.3 \\
\hline & Non-vegetarian & 43 & 71.7 \\
\hline & Mixed & - & - \\
\hline \multirow{2}{*}{ Educational status } & Plus two & 38 & 63.3 \\
\hline & Plus one & 22 & 36.7 \\
\hline \multirow{3}{*}{ Family income (Rs.) } & $<5000$ & 28 & 46.7 \\
\hline & $5001-10000$ & 28 & 46.7 \\
\hline & $10001-15000$ & 3 & 5.0 \\
\hline
\end{tabular}




\begin{tabular}{|c|c|c|c|}
\hline \multirow{2}{*}{ Characteristics } & \multirow{2}{*}{ Category } & \multicolumn{2}{|c|}{ Respondents } \\
\hline & & Number & Percent (\%) \\
\hline & $15001-20000$ & 1 & 1.7 \\
\hline & 20000 and above & - & - \\
\hline \multirow{4}{*}{ Religion } & Hindu & 45 & 75.0 \\
\hline & Christian & 10 & 16.7 \\
\hline & Muslim & 5 & 8.3 \\
\hline & Others & - & - \\
\hline \multirow{3}{*}{ Type of family } & Nuclear family & 37 & 61.7 \\
\hline & Joint family & 21 & 35.0 \\
\hline & Extended family & 2 & 3.3 \\
\hline \multirow{2}{*}{ Family history of PCOS } & Yes & 13 & 31.7 \\
\hline & No & 47 & 68.3 \\
\hline \multirow{5}{*}{ Source of information } & Friends & 6 & 10.0 \\
\hline & Relatives & 19 & 31.7 \\
\hline & Health personnel & 32 & 53.3 \\
\hline & Mass media & 3 & 5.0 \\
\hline & Other specify & - & - \\
\hline
\end{tabular}

Table 2: Mean and SD of knowledge scores before and after STP and statistical significance $(\mathrm{N}=60)$.

\begin{tabular}{|c|c|c|c|c|c|c|}
\hline \multirow{2}{*}{ Aspects of knowledge } & \multirow{2}{*}{$\begin{array}{l}\text { Max. } \\
\text { score }\end{array}$} & \multicolumn{3}{|c|}{ Enhancement } & \multirow[b]{2}{*}{ t value } & \multirow[b]{2}{*}{$P$ value } \\
\hline & & Mean & SD & Mean \% & & \\
\hline Anatomy and physiology of reproductive system & 16 & 8.02 & 2.14 & 50.1 & $6.846^{*}$ & $<0.05$ \\
\hline Meaning of PCOS & 2 & 0.66 & 0.42 & 33.0 & $7.096^{*}$ & $<0.05$ \\
\hline Risk factors of PCOS & 3 & 0.98 & 0.38 & 32.6 & $8.916^{*}$ & $<0.05$ \\
\hline Pathology and Manifestation & 5 & 1.86 & 0.74 & 37.2 & $9.012^{*}$ & $<0.05$ \\
\hline Detection and management & 5 & 2.00 & 0.93 & 40.0 & $10.41^{*}$ & $<0.05$ \\
\hline General care & 3 & 1.19 & 0.43 & 39.6 & $9.32^{*}$ & $<0.05$ \\
\hline Over all & 34 & 12.8 & 2.31 & 37.6 & $27.98^{*}$ & $<0.05$ \\
\hline
\end{tabular}

*Significant at $5 \%$ level for $59 \mathrm{df}$ (i.e.; $\mathrm{p}<0.05)$.

Table 3: Association between knowledge and selected demographic variables of adolescent girls.

\begin{tabular}{|c|c|c|c|c|c|c|c|c|c|}
\hline \multirow{3}{*}{ Demographic variables } & \multirow{3}{*}{ Category } & \multirow{2}{*}{\multicolumn{2}{|c|}{ Sample }} & \multicolumn{4}{|c|}{ Knowledge } & \multirow{3}{*}{$\begin{array}{l}\text { Chi- } \\
\text { square } \\
\text { value }\end{array}$} & \multirow{3}{*}{ P value } \\
\hline & & & & $\leq \mathrm{me}$ & ian & $>$ me & & & \\
\hline & & No. & $\%$ & No. & $\%$ & No. & $\%$ & & \\
\hline \multirow{4}{*}{ Age (years) } & Below 16 & - & - & - & - & - & - & \multirow{4}{*}{$\begin{array}{l}0.268, \\
\mathrm{df}=1, \mathrm{NS}\end{array}$} & \multirow{4}{*}{$>0.05$} \\
\hline & $16-17$ & 30 & 50.0 & 17 & 53.1 & 13 & 46.4 & & \\
\hline & $18-19$ & 30 & 50.0 & 15 & 46.9 & 15 & 53.6 & & \\
\hline & 20 and above & - & - & - & - & - & - & & \\
\hline \multirow{4}{*}{ Age at menarche (years) } & Below 12 & 5 & 8.3 & 3 & 6.3 & 2 & 7.2 & \multirow{4}{*}{$\begin{array}{l}8.613, \\
d f=3, S\end{array}$} & \multirow{4}{*}{$<0.05$} \\
\hline & $13-14$ & 23 & 38.3 & 16 & 50.0 & 7 & 25.0 & & \\
\hline & $15-16$ & 32 & 53.3 & 13 & 40.7 & 19 & 67.8 & & \\
\hline & $>16$ & - & - & - & - & - & - & & \\
\hline \multirow{3}{*}{ Menstrual pattern } & Irregular & 41 & 68.3 & 23 & 71.9 & 18 & 64.3 & \multirow{3}{*}{$\begin{array}{l}0.397 \\
\mathrm{df}=1, \mathrm{NS}\end{array}$} & \multirow{3}{*}{$>0.05$} \\
\hline & Regular & 19 & 31.7 & 9 & 28.1 & 10 & 35.7 & & \\
\hline & Anovulation & - & - & - & - & - & - & & \\
\hline \multirow{3}{*}{ Pain present } & Mild & 33 & 55.0 & 12 & 37.5 & 21 & 75.0 & \multirow{3}{*}{$\begin{array}{l}8.01, \\
d f=2, S\end{array}$} & \multirow{3}{*}{$<0.05$} \\
\hline & Moderate & 24 & 40.0 & 18 & 56.3 & 6 & 21.4 & & \\
\hline & Severe & 3 & 5.0 & 2 & 6.3 & 1 & 3.6 & & \\
\hline \multirow{3}{*}{ Dietary pattern } & Vegetarian & 17 & 28.3 & 7 & 21.9 & 10 & 35.7 & \multirow{3}{*}{$\begin{array}{l}1.409, \\
\mathrm{df}=1, \mathrm{NS}\end{array}$} & \multirow{3}{*}{$>0.05$} \\
\hline & Non-vegetarian & 43 & 71.7 & 25 & 78.1 & 18 & 64.3 & & \\
\hline & Mixed & - & - & - & - & - & - & & \\
\hline \multirow{2}{*}{ Educational status } & Plus two & 38 & 63.3 & 21 & 65.6 & 17 & 60.7 & \multirow{3}{*}{$\begin{array}{l}0.155, \\
\mathrm{df}=1, \mathrm{~N} \\
1.645,\end{array}$} & \multirow{2}{*}{$>0.05$} \\
\hline & Plus one & 22 & 36.7 & 11 & 34.4 & 11 & 39.3 & & \\
\hline Family income (Rs.) & $<5000$ & 28 & 46.7 & 14 & 43.8 & 14 & 50.0 & & $>0.05$ \\
\hline
\end{tabular}

Continued. 


\begin{tabular}{|c|c|c|c|c|c|c|c|c|c|}
\hline \multirow{3}{*}{ Demographic variables } & \multirow{3}{*}{ Category } & \multirow{2}{*}{\multicolumn{2}{|c|}{ Sample }} & \multicolumn{4}{|c|}{ Knowledge } & \multirow{3}{*}{$\begin{array}{l}\text { Chi- } \\
\text { square } \\
\text { value }\end{array}$} & \multirow{3}{*}{ P value } \\
\hline & & & & \multicolumn{2}{|c|}{$\leq$ median } & \multicolumn{2}{|c|}{ >median } & & \\
\hline & & No. & $\%$ & No. & $\%$ & No. & $\%$ & & \\
\hline & $5001-10000$ & 28 & 46.7 & 16 & 50.0 & 12 & 42.9 & $\mathrm{df}=3, \mathrm{NS}$ & \\
\hline & $10001-15000$ & 3 & 5.0 & 2 & 6.2 & 1 & 3.6 & & \\
\hline & $15001-20000$ & 1 & 1.7 & 0 & 0 & 1 & 3.6 & & \\
\hline & $>20000$ & - & - & - & - & - & - & & \\
\hline \multirow{4}{*}{ Religion } & Hindu & 45 & 75.0 & 24 & 75.0 & 21 & 75.0 & \multirow{4}{*}{$\begin{array}{l}0.472, \\
\mathrm{df}=2, \mathrm{NS}\end{array}$} & \multirow{4}{*}{$>0.05$} \\
\hline & Christian & 10 & 16.7 & 6 & 18.7 & 4 & 14.3 & & \\
\hline & Muslim & 5 & 8.3 & 2 & 6.2 & 3 & 10.7 & & \\
\hline & Others & - & - & - & - & - & - & & \\
\hline \multirow{3}{*}{ Type of family } & Nuclear & 37 & 61.7 & 19 & 59.4 & 18 & 64.3 & \multirow{3}{*}{$\begin{array}{l}1.431, \\
\mathrm{df}=2, \mathrm{NS}\end{array}$} & \multirow{3}{*}{$>0.05$} \\
\hline & Joint & 21 & 35.0 & 13 & 40.6 & 8 & 28.6 & & \\
\hline & Extended & 2 & 3.3 & 0 & 0 & 2 & 7.1 & & \\
\hline \multirow{2}{*}{ Family history of PCOS } & Yes & 13 & 21.7 & 10 & 31.2 & 3 & 10.7 & \multirow{2}{*}{$\begin{array}{l}4.229, \\
d f=1, S\end{array}$} & \multirow{2}{*}{$<0.05$} \\
\hline & No & 47 & 68.3 & 22 & 68.8 & 25 & 89.3 & & \\
\hline \multirow{4}{*}{ Source of information } & Friends & 6 & 10.0 & 3 & 9.4 & 3 & 10.7 & \multirow{4}{*}{$\begin{array}{l}0.668, \\
d f=3, N S\end{array}$} & \multirow{4}{*}{$>0.05$} \\
\hline & Relatives & 19 & 31.7 & 11 & 34.4 & 8 & 28.6 & & \\
\hline & Health personnel & 32 & 53.3 & 17 & 53.1 & 15 & 53.6 & & \\
\hline & Mass media & 3 & 5.0 & 1 & 3.1 & 2 & 7.1 & & \\
\hline
\end{tabular}

Note: S- significant at $5 \%$ level for 59 df (i.e.; $p<0.05$ ); NS- not significant at $5 \%$ level $(p>0.05)$.

\section{Adolscent girls according to level of knowledge before STP}

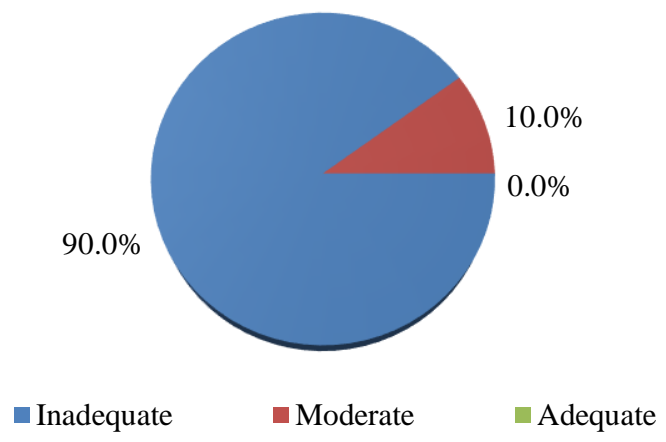

Figure 1: Distribution of adolescent girls according to level knowledge before STP.

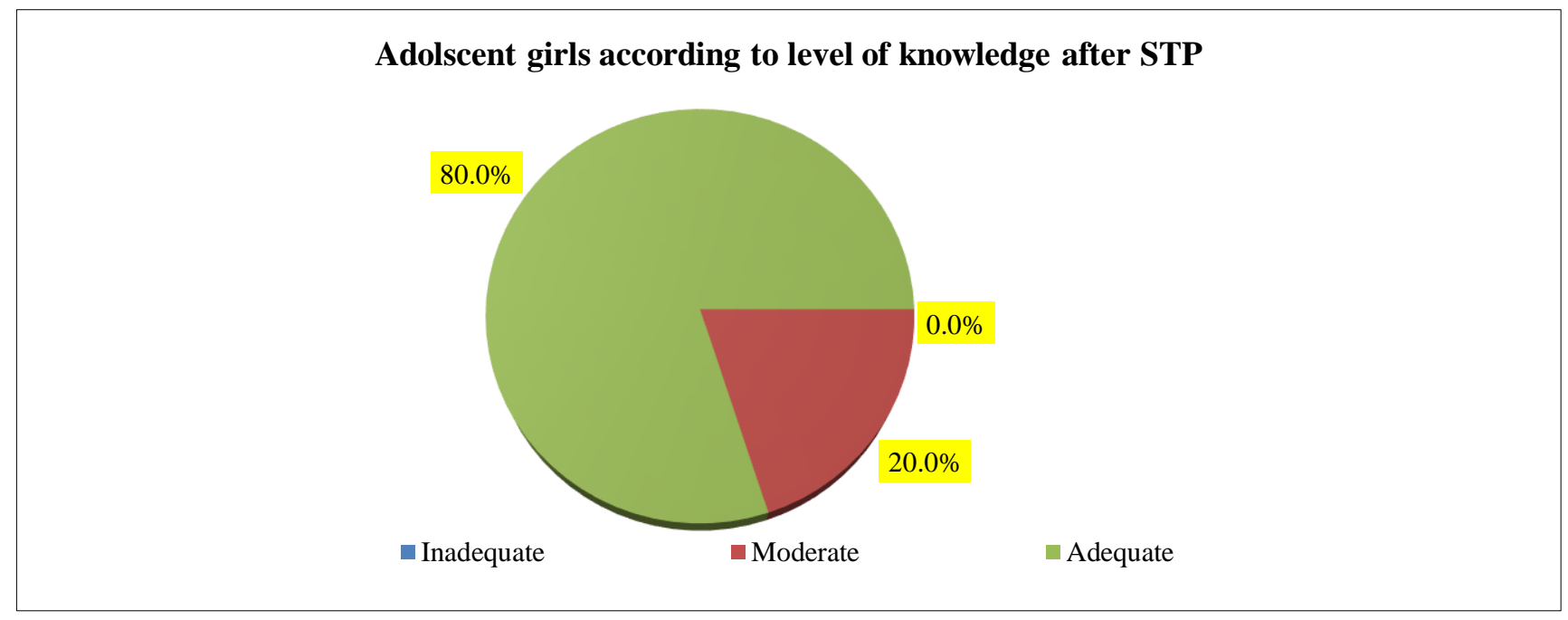

Figure 2: Distribution of adolescent girls according to level knowledge after STP. 


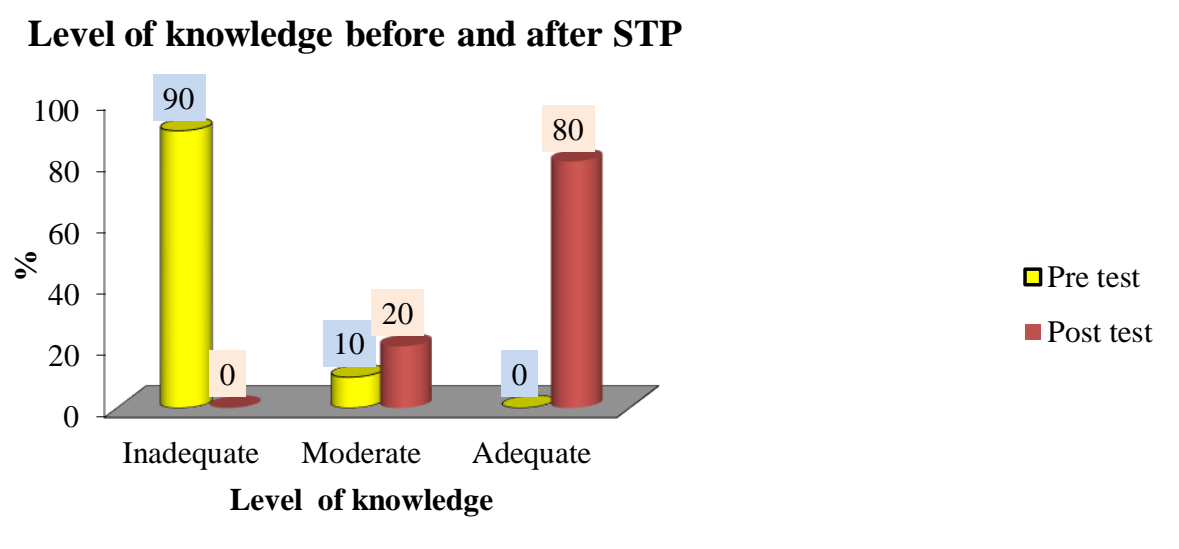

Figure 3: Distribution of adolescent girls according to level of knowledge before and after STP.

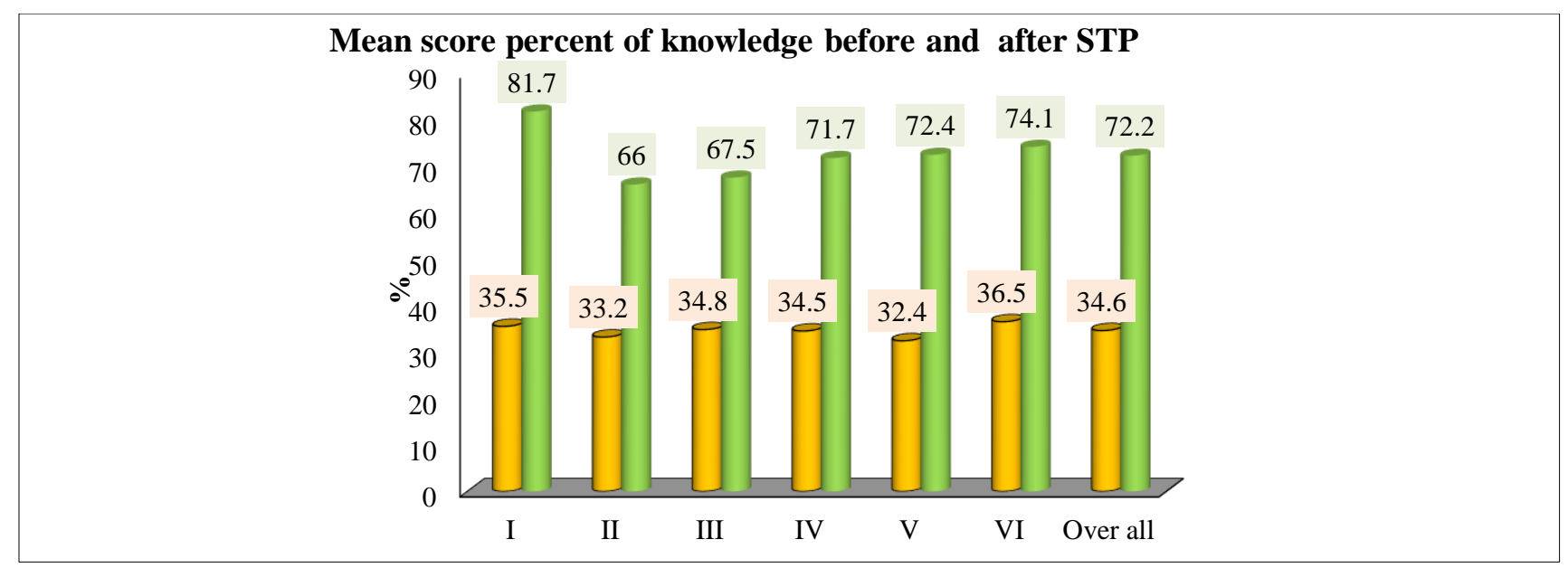

Figure 4: Mean score percent of knowledge among adolescent girls before and after STP.

\section{DISCUSSION}

Current study showed (Figure 3) a majority, 90.0\% (54) had inadequate knowledge, $10.0 \%$ (6) had moderate knowledge and none of them had adequate knowledge STP. But, a majority, $80.0 \%$ (48) had adequate knowledge, $20.0 \%$ (12) had moderate knowledge and none of them had inadequate knowledge after STP. The finding of the present study was supported by the study done by Davies MJ, Lord J 'Health education on knowledge on polycystic ovarian syndrome' adolescent girls had little knowledge on PCOS. Of them, $53.7 \%$ had moderate knowledge, while $66.2 \%$ of adolescent girls were interested in need to improve by providing knowledge and information through sources such as radio, television, door-to-door campaigning and interpersonal communications. 30\% emphasized the need to improve the availability and quality of services. This study indicated that a pressing need for effective intervention strategies, both at the community and the clinic level. ${ }^{20}$

In order to evaluate the effectiveness of STP on knowledge regarding PCOS among adolescent girls the following research hypothesis was formulated.
$\mathrm{H}_{1:}$ 'There is a significant difference between the mean pre and post-test knowledge regarding PCOS among adolescent girls' with null hypothesis that $\mathrm{H}_{01}$ : 'There is no significant difference between the mean pre and post-test level of knowledge regarding polycystic ovarian syndrome among adolescent girls.

The paired t-test (Table 2) was carried out and it was found to be invariably significant at $p<0.05$ level of significance, hence null hypothesis $\left(\mathrm{H}_{01}\right)$ was rejected and research hypothesis $\mathrm{H}_{1}$ was accepted. Its evidence that the structured teaching programme on knowledge is significantly effective on improving the knowledge regarding PCOS among adolescent girls.

The statistical outcomes of association between socio demographic characters of adolescent girls with knowledge regarding polycystic ovarian syndrome (Table 3 ) showed that the variables, age at menarche $\left(\chi^{2}=8.613\right.$, $\mathrm{df}=2)$, pain present during menstruation $\left(\chi^{2}=8.01, \mathrm{df}=2\right)$ and family history of $\operatorname{PCOS}\left(\chi^{2}=4.229, \mathrm{df}=1\right)$ were found to be statistically significant with knowledge at $5 \%$ level i.e.; $p<0.05$. The remaining characters were not found to be statistically significant i.e.; $p>0.05$. It evidenced that the 
knowledge influenced by age at menarche, pain present during menstruation and family history of PCOS of adolescent girls.

The hypothesis $\mathrm{H}_{2}$ : 'There was a significant association between post-test knowledge regarding PCOS among adolescent girls with their selected demographic variables' with null hypothesis $\mathrm{H}_{02}$ : 'There was no significant association between post-test knowledge regarding PCOS among adolescent girls with their selected demographic variables'. The study evidenced that there is a significant association between knowledge scores and selected sociodemographic variables of adolescent girls. Limitations of the present study were only a small sample of sixty adolescent girls are the samples and only the adolescent girls of selected primary schools are taken as samples, so there was limited possibility of generalization.

\section{CONCLUSION}

Researcher concluded that the structured teaching programme was significantly effective in increasing the knowledge of PCOS.

\section{Funding: No funding sources}

Conflict of interest: None declared

Ethical approval: The study was approved by the Institutional Ethics Committee

\section{REFERENCES}

1. Barnard L, Ferriday D, Guenther N, Strauss B, Balen AH, Dye L. Quality of life and psychological well being in polycystic ovary syndrome. Hum Reprod. 2007;22(8):2279-86.

2. Christine CR, Didier D. Diagnosis of Hyperandrogenism in Female Adolescents, 2006. Available at: http://www.health.am/gyneco/more/diagnosisofhyperan drogenism-in-female/. Accessed on 1 May 2021.

3. Cocksedge KA, Li TC, Saravelos SH, Metwally M. A reappraisal of the role of polycystic ovary syndrome in recurrent miscarriage. Reprod Biomed Online. 2008;17(1):151-60.

4. Pillittire A. Maternal and child health nursing. 6th ed. Lippincott Publishers; 2009: 916.

5. Azziz R. Controversy in clinical endocrinology: diagnosis of polycystic ovarian syndrome: the Rotterdam criteria are premature. J Clin Endocrinol Metab. 2006;91(3):781-5.

6. Carmina E. Diagnosis of polycystic ovary syndrome: from NIH criteria to ESHRE-ASRM guidelines. Minerva Ginecol. 2004;56(1):1-6.
7. Pedersen SD, Brar S, Faris P, Corenblum B. Polycystic ovary syndrome: validated questionnaire for use in diagnosis. Can Fam Physician. 2007;53(6):1042-7.

8. Somani N, Harrison S, Bergfeld WF. The clinical evaluation of hirsutism. Dermatol Ther. 2008;21(5):37691.

9. Sharquie KE, Bayatti AA, Ajeel AI, Bahar AJ, Nuaimy AA. Free testosterone, luteinizing hormone/follicle stimulating hormone ratio and pelvic sonography in relation to skin manifestations in patients with polycystic ovary syndrome. Saudi Med J. 2007;28(7):1039-43.

10. Robinson S, Rodin DA, Deacon A, Wheeler MJ, Clayton $\mathrm{RN}$. Which hormone tests for the diagnosis of polycystic ovary syndrome?, $\mathrm{Br}$ J Obstet Gynaecol. 1992;99(3):232-8.

11. Li X, Lin JF. Clinical features, hormonal profile, and metabolic abnormalities of obese women with obese polycystic ovary syndrome. Zhonghua Yi Xue Za Zhi. 2005;85(46):3266-71.

12. Banaszewska B, Spaczynski RZ, Pelesz M, Pawelczyk L. Incidence of elevated LH/FSH ratio in polycystic ovary syndrome women with normo- and hyperinsulinemia. Rocz Akad Med Bialymst. 2003;48:131-4.

13. Bhattacharya SM, Jha A. Prevalence and risk of depressive disorders in women with polycystic ovary syndrome (PCOS). Fertil Steril. 2010;94(1):357-9.

14. Creatsas G, Deligeoroglou E. Polycystic ovarian syndrome in adolescents. Curr Opin Obstet Gynecol. 2007;19(5):420-6.

15. Kamboj MK, Bonny AE. Polycystic ovary syndrome in adolescence: diagnostic and therapeutic strategies. Transl Pediatr. 2017;6(4):248-55.

16. Hashemipour M, Faghihimani S, Zolfaghary B, Hovsepian S, Ahmadi F, Haghighi S. Prevalence of polycystic ovary syndrome in girls aged $14-18$ years in Isfahan, Iran. Horm Res. 2004;62(6):278-82.

17. Siklar Z, Oçal G, Adiyaman P, Ergur A, Berberoglu M. Functional ovarian hyperandrogenism and polycystic ovary syndrome in prepubertal girls with obesity and/or premature pubarche. J Pediatr Endocrinol Metab. 2007;20(4):475-81.

18. Ergur A, Berberoğlu M. Functional ovarian hyperandrogenism and polycystic ovary syndrome in prepubertal girls with obesity and/or premature pubarche. J Pediatr Endocrinol Metab. 2007 Apr; 20(4):475-81.

19. Buczkowska E, Jarosz CP, Deja G. Early metabolic abnormalities--insulin resistance, hyperinsulinemia, impaired glucose tolerance and diabetes, in adolescent girls with polycystic ovarian syndrome. Przegl Lek. 2006;63(4):234-8.

20. Davies MJ, Lord J. Health education on knowledge on polycystic ovarian syndrome. Nursing J India. 2004;27698.

Cite this article as: John S. Effectiveness of structure teaching programme regarding polycystic ovarian syndrome among adolescent girls. Int $\mathrm{J}$ Reprod Contracept Obstet Gynecol 2021;10:2818-4. 